Recebido: $22 / 05 / 2017$

Aprovado: 02/11/2017

\title{
Saúde Pública em mau Estado: a carne para consumo nos debates sobre higiene pública na Gazeta Médica da Bahia na década de 1860
}

Vanessa de Jesus Queiroz

Resumo: Este artigo aborda o tema da higiene pública na Gazeta Medica da Bahia na década de 1860. Higiene pública é aqui entendida como o conjunto de normas sanitárias que devem ser seguidas em nome da manutenção do bem comum, mensurado pela ausência de doenças e problemas causados por fugas a tais normas. Aparece como campo necessário e direto da saúde pública. A elaboração, bem como a execução e a manutenção das regras da higiene, ensejam um campo ora conflituoso, ora pactual, de debates que envolvem diversas parcelas sociais, das quais destacamos imprensa médica e classe médica na Bahia, bem como as diversas relações envolvendo órgãos fiscalizadores, governo e população geral, numa complexa rede relacional que conseguimos identificar nas entrelinhas do jornal médico em questão.

Palavras-Chave: Higiene Pública; Saúde Pública; Gazeta Medica da Bahia.

Abstract: This article aims to analyze public hygiene in the newspaper Gazeta Medica da Bahia in the 1860s. Public hygiene is understood here as a set of health rules which should be followed for maintaining the common good, measured by the absence of diseases and problems caused by disregard to such rules. It is a necessary and direct field of public health. The elaboration, as well as the execution and maintenance of the rules of hygiene, give rise to sometimes conflictual, sometimes covenant, field of debates that involve diverse social parcels. Here we highlight the medical press and medical class in Bahia, as well as the various relationships involving oversight agencies, government and population, in a complex relational network that we can identify between the lines of the medical journal in question.

Keywords: Public Hygiene; Public Health; Gazeta Medica da Bahia.

\footnotetext{
* Mestranda pelo PPGHIS/UnB, bolsista CAPES. E-mail: vanessa_djq@hotmail.com.
} 


\section{Considerações introdutórias: Carne Fraca, conflitos diversos e algumas permanências}

No mês de março de 2017 grassavam nos jornais, na internet, nos noticiários televisivos e noutros meios de comunicação, notícias referentes à polêmica Operação Carne Fraca ${ }^{l}$. Tal operação foi implantada com o intuito de investigar empresas frigoríficas nacionais acusadas de adulteração de carnes comercializadas no mercado interno e externo. Apesar de ter ganhado maiores proporções no âmbito público em março de 2017, as investigações que possibilitaram a deflagração da operação ocorrem desde 2015, conforme consta no relatório da Polícia Federal. $^{2}$

Algumas das conclusões investigativas da operação foram:

(...) $\mathrm{O}$ que se verificou foi a existência de organizações criminosas estruturadas no âmbito da SFA/PR, envolvendo sua mais alta cúpula, além de crimes envolvendo outras unidades da Federação e o próprio Ministério da Agricultura, Pecuária e Abastecimento (MAPA) (...) Os crimes cometidos por tais organizações afetam diretamente a saúde pública pela omissão daqueles que deveriam fiscalizar e pelos interesses escusos de empresários comercializam produtos alimentícios em desacordo com as normas, colocando em risco à saúde dos consumidores (...) os efeitos da ingestão de alimentos impróprios muitas vezes só serão percebidos a longo prazo e sem que se possa aferir suas causas, já que tais alimentos continham a "chancela" do órgão que deveria fiscalizar e não o fez... ${ }^{3}$

O trecho destacado evidencia um conflito a nível de rede relacional. A investigação da fraude alimentícia em questão envolve e afeta, de diferentes maneiras, funcionários, empresários, fiscais, instituições públicas e privadas, imprensa, público consumidor e opinião pública, além do governo brasileiro, tendo em vista que a adulteração de carnes é assunto que impacta diretamente as esferas econômica, política e sociocultural.

A título de breve exemplificação, cabe mencionar que a comprovação da carne adulterada pode resultar no corte de relações de exportação, o que seria prejudicial ao PIB

\footnotetext{
${ }^{1}$ Inquérito Policial n. 0136/2015-SR/PF/PR. A investigação que ensejou a Operação Carne Fraca teve início com uma denúncia sobre possível fraude em carnes servidas na merenda de uma escola do Paraná. Tal denúncia foi feita por um fiscal federal agropecuário de nome Daniel Gouvêa Teixeira, que desde 2014 verificou a ocorrência de corrupção na política fiscalizadora no frigorífico PECCIN e foi exonerado e rebaixado de cargo pouco tempo após tal ato denunciador à instância superior, chefiada por Maria do Rocio Nascimento. Tal alteração de status de cargo também constituiu parte da investigação.

${ }^{2}$ Disponivel

em:

$<$ http://politica.estadao.com.br/blogs/fausto-macedo/wpcontent/uploads/sites/41/2017/04/246_REL_FINAL_IPL1.pdf>. Acesso em maio de 2017.

${ }^{3}$ Ibid., p. 8
} 
brasileiro $^{4}$, fator diretamente ligado ao crescimento econômico do país. $\mathrm{Na}$ área sociocultural, pode resultar em mudanças bruscas de hábitos alimentares, a partir de desconfianças e descontentamentos ${ }^{5}$, e consequentes deficiências nutricionais que podem ocasionar doenças em proporção de calamidade pública. Os efeitos tornam-se ainda mais alarmantes quando pensamos que as esferas sociais, culturais, econômicas e políticas se inter-relacionam.

Tanto do trecho apontado quanto da leitura completa do relatório, observa-se que questão central que fornece substância à Operação Carne Fraca é a preocupação com a manutenção da saúde dos consumidores, diretamente prejudicada por um esquema de fraude onde os órgãos fiscalizadores deixam de cumprir as normas estabelecidas por um código de higiene alimentar que zela pela saúde pública. É válido ressaltar algumas palavras extraídas de nota da Agência Nacional de Vigilância Sanitária- ANVISA, quanto à operação:

Em relação à Operação "Carne Fraca” realizada pela Polícia Federal para investigar possíveis adulterações no processamento das carnes e seus derivados, a Anvisa vem esclarecer: $\mathrm{O}$ controle e fiscalização de alimentos no Brasil é uma responsabilidade compartilhada entre órgãos e entidades da Administração Pública, com destaque aos órgãos da agricultura, da pecuária e do Sistema Único de Saúde, com responsabilidades e atribuições distintas. O Ministério da Agricultura, Pecuária e Abastecimento - MAPA é responsável pelo normatização e controle dos abatedouros, frigoríficos e das indústrias de processamento de produtos de origem animal, a exemplo de carnes e seus produtos derivados, bem como pela garantia da qualidade desses produtos. À Anvisa compete o estabelecimento das normas relativas aos aditivos permitidos a serem utilizados em alimentos, em consonância com mecanismos internacionais de harmonização, como o Codex Alimentarius - mecanismo conjunto da Organização Mundial da Saúde (OMS) e da Organização das Nações Unidas para Alimentação e Agricultura (FAO), aos padrões de embalagem, incluindo a rotulagem para alimentos, e aos limites para resíduos de medicamentos veterinários. O Sistema Nacional de Vigilância Sanitária também atua, de forma complementar à fiscalização dos órgãos da agricultura, no controle dos estabelecimentos comerciais: serviços de alimentação, supermercados e açougues, dentre outros. A Anvisa solicitou ao MAPA e à Policia Federal as informações sobre os produtos

\footnotetext{
${ }^{4}$ O Produto Interno Bruto (PIB) do Brasil chegou a R \$5,9 trilhões em 2015, registrando queda de 3,85\% sobre o resultado anterior. O PIB do agronegócio alcançou $\mathrm{R} \$ 1,26$ trilhão, representando $21 \%$ do PIB total brasileiro. Já o PIB da pecuária chegou a R $\$ 400,7$ bilhões, 30\% do agronegócio brasileiro. Em 2015, o saldo da balança comercial brasileira foi de US $\$ 19,69$ bilhões. As exportações do agronegócio, que atingiram US\$88,22 bilhões, contribuíram para o saldo positivo do setor, que por sua vez foi fundamental para o saldo positivo da balança comercial brasileira. ("Perfil da Pecuária no Brasil- relatório anual de 2016", disponível em: <http://www.beefpoint.com.br/cadeia-produtiva/giro-do-boi/perfil-da-pecuaria-no-brasil-relatorio-anual-2016> Acesso em abril de 2017)

${ }^{5}$ Impulsionadas, também, pela propagação de boatos. Em nosso caso, citamos alguns rumores constantemente publicados em redes sociais como twitter e facebook: Muitas pessoas começaram a falar que havia papelão nas carnes distribuídas à população. Vale ressaltar que relatórios oficiais provindos da verificação da agência fiscalizadora do MAPA não constataram a presença de tal elemento nas carnes averiguadas.
} 
investigados, com seus respectivos lotes, datas de fabricação e laudos de análises que tenham sido realizadas, dados indispensáveis para que a atividade fiscalizatória seja realizada em pontos de varejo. Tais informações serão imediatamente repassadas às Secretarias Estaduais e Municipais de Saúde, orientando as mesmas nas ações de inspeção dos produtos das empresas investigadas pela Operação "Carne Fraca". Essas ações devem ser realizadas de forma integrada e complementar com as inspeções dos órgãos de fiscalização agropecuária, utilizando as normativas específicas de cada órgão. Os alimentos porventura apreendidos no comércio varejista serão encaminhados para análise laboratorial, a fim de se verificar possíveis irregularidades. Casos haja a comprovação de irregularidades, a Anvisa tomará todas as medidas previstas pela legislação sanitária, como multas, recolhimento de produtos e até interdição de estabelecimentos comerciais. ${ }^{6}$

A nota da ANVISA ressalta a responsabilidade compartilhada, ou seja: há uma rede hierárquica e necessariamente relacional entre os próprios órgãos fiscalizadores, a partir de diferentes atribuições de tarefas que variam desde procedimentos investigativos à aplicação de ações punitivas. Além disso, a nota parece ter o objetivo de explicar que, ainda que seja o órgão nacional referência no que concerne a vigilância sanitária, a ANVISA não deve ser totalmente responsabilizada pelos problemas relatados, tendo em vista que depende de outras instâncias para atuar de forma eficaz. Responsabilidade e atuação são partilhadas entre os diferentes agentes fiscalizadores, designados e autorizados pelo Governo Federal.

O relatório da Operação Carne Fraca expõe uma extensa trama de acordos, subornos e fraudes envolvendo fiscais, funcionários, empresários e órgãos fiscalizadores do governo, além da população, afetada pela trama. O bom estado da carne, ou seja, aquele que segue devidamente aos padrões da higiene em nome da saúde pública, movimenta a extensa rede pactual e conflituosa brevemente exposta.

Do que foi dito até aqui, algumas indagações ascendem: Porque o trecho conclusivo que reproduzimos, parte do relatório, parece generalizar todo o serviço fiscalizador se a operação foi ensejada a partir das denúncias de um só fiscal sanitário? De que modo a imprensa veiculou a notícia? Em que medida a imprensa tem maior influência do que os documentos oficiais disponibilizados, inclusive, on-line? Qual o alcance social de um relatório oficial e qual seu público-alvo?

6 Publicada em 21 de março de 2017. Disponível em: <http://portal.anvisa.gov.br/noticias//asset_publisher/FXrpx9qY7FbU/content/nota-da-anvisa-sobre-a-operacao-carne-fraca/219201/pop_up?_101_INSTANCE_FXrpx9qY7FbU_viewMode=print\&_101_INSTANCE_FXrpx9qY7FbU_la nguageId=pt_BR> Acesso em maio de 2017. 
Não é nosso objetivo, aqui, responder a tais perguntas. Contudo a reflexão sobre elas nos permite elencar alimentação, como campo da saúde pública, um importante problema social. O exemplo da Operação Carne Fraca nos permite verificar permanências em meio a contextos diversos. Num contexto onde vigorava uma concepção de saúde pública diferente da nossa, a questão da salubridade da carne já invadia as folhas de jornais do século XIX aparecendo como importante debate que envolvia, também, uma rede de instituições e pessoas.

Neste artigo apresentaremos significações da higiene pública propostas no periódico Gazeta Medica da Bahia (GMB) na década de 1860. Respaldo de nossos argumentos serão análises de publicações dos anos de 1866 a 1869, incluindo quatro publicações de textos que colocam a questão do bom estado de salubridade da carne como requisito necessário à manutenção da saúde pública ou ao menos como questão central da higiene pública.

Em nossas considerações quanto à rede de pessoas e instituições inseridas na temática em questão nos amparamos, principalmente, em três autores: Gabriela dos Reis Sampaio, Giovanni Levi e George Rosen.

Em sua obra "Nas Trincheiras da Cura", importante contribuição à discussão sobre significados sociais da medicina do Brasil Império, Gabriela Sampaio desnaturaliza noções de medicina e classe médica como coisas coesas, unas. São apresentadas disputas que ocorriam a nível externo: os diplomados tentando se legitimar frente aos não diplomados, chamados por aqueles de "charlatões"; e interno: quando os que se diziam representantes da medicina científica não conseguiam chegar a um consenso entre si e conflitavam nas teorias explicativas sobre assuntos de doença e cura. Também presente era a disputa entre médicos e autoridades da época.

A autora nos mostra, também, a relevância da imprensa como palco dos debates e embates médicos do período, além de outros argumentos deveras importantes. Aqui buscaremos, a partir dos escritos de um jornal, pensar nos empecilhos enfrentados por uma classe médica que buscava tornar-se legítima sob o pretexto da higiene pública, daí nos valermos de reflexões que seguem linha de raciocínio semelhante à de Gabriela Sampaio.

\footnotetext{
${ }^{7}$ Nas Trincheiras da Cura. As diferentes medicinas no Rio de Janeiro Imperial. Campinas, SP: Editora da UNICAMP, 2001.
} 
Quanto a Giovanni Levi, absorvemos duas perspectivas fundamentais extraídas da leitura do capítulo "Três Histórias de Família: os núcleos parentais"8. A primeira é a que indica que não se deve tratar a fonte documental como algo absoluto e imparcial. $\mathrm{O}$ autor nos conta que a documentação analisada por ele foi produzida a partir de comportamentos institucionalmente reconhecidos (LEVI, 2000:89). Assim sendo, a análise documental deve tomar o cuidado de assumir a possibilidade de artimanhas, paixões, incertezas e outros influentes que não aparecem nas páginas regidas por um modelo cartorial (LEVI, 2000:90). Junto à informação a fonte produz silêncio. Nas entrelinhas é possível identificar algumas dessas vozes indispensáveis que não ocupam lugar explícito, a exemplo das estratégias. Identificá-las é um processo que exige cuidado. Foi com este olhar que buscamos analisar nossa fonte principal, a Gazeta Médica da Bahia.

A segunda provém da exposição das relações familiares como não estritamente rígidas e guiadas unicamente por preceitos econômicos e biológicos (LEVI, 2000:112). Levi apresenta uma rede de relações que ultrapassa os vínculos meramente sanguíneos, ou seja: os mais evidentes (LEVI, 2000:126). Aqui, buscamos questionar parâmetros de obviedade e/ou homogeneidade que parecem estar contidos em expressões como "classe médica", "medicina", "higiene pública", cujos significados ultrapassam a etimologia e muito revelam daqueles que as usam. Identificamos uma rede de relações que transparece nas páginas da Gazeta Médica da Bahia, demonstrando que estas expressões adquirem significados múltiplos.

Corroboramos com o conceito de saúde pública proposto por George Rosen. Este enfatiza a relação entre doenças e seus efeitos sobre a vida em comunidade que envolve áreas como habitação, alimentação, relações entre sistemas de autoridade governamental e população, produtividade econômica, crenças, entre outros (ROSEN,1994). O autor nos fala sobre a importância de compreender as doenças não apenas como fenômenos biológicos, mas também como fenômenos sociais, econômicos, políticos e culturais (ROSEN,1994:21).

$\mathrm{O}$ artigo está estruturado em três partes. Na primeira, lançamos considerações acerca dos personagens classe médica e imprensa médica. São expostos intuitos principais dos responsáveis pela publicação e discutidos alguns porquês de se lançar uma gazeta médica. Refletimos sobre como a Gazeta Medica da Bahia significava higiene pública e justificava

\footnotetext{
${ }^{8}$ Capítulo 2 da obra A herança imaterial. Trajetória de um exorcista no Piemonte do século XVII. Rio de Janeiro: Civilização Brasileira, 2000, 87- 130.
} 
debates a ela relacionados. Na segunda parte, buscamos identificar a rede de relações evidenciadas pela carne como questão de saúde e higiene pública. O binômio regional e central é problematizado, sobretudo a partir da exposição da relação hierárquica entre inspetorias de saúde pública provinciais e Junta Central de Higiene Pública. A terceira parte conclui o artigo. Nela lançamos breves reflexões sobre um personagem quase silenciado na fonte: a população.

As considerações ancoram-se majoritariamente em leitura e crítica da fonte, além do uso de legislações, bibliografia e outros recursos (a exemplo de nota oficial da ANVISA) devidamente indicados ao longo do texto.

\section{Classe médica, imprensa médica e a missão de esclarecer e guiar o homem: A Higiene Pública na Gazeta Medica da Bahia (GMB) na década de 1860.}

Em 10 de Julho de 1866 era lançado o primeiro número da Gazeta Medica da Bahia $(G M B)$, jornal de periodicidade quinzenal publicado por um grupo de facultativos residentes na Bahia9. Tais facultativos faziam parte do corpo docente da Faculdade de Medicina da Bahia e/ou atuavam em clínicas civis, hospitais militares e Santa Casa de Misericórdia, além de praticarem visitas e atendimentos domiciliares.

Abaixo, algumas palavras contidas no programa de lançamento da $G M B$ :

O nosso propósito é simplesmente o seguinte: concentrar, quanto for possivel, os elementos activos da classe medica, afim de que, mais unidos e fortificando-se mutuamente, concorram para augmentar-lhes os creditos, e a consideração publica; diffundir todos os conhecimentos que a observação propria ou alheia nos possa revelar; acompanhar o progresso da sciencia nos paizes mais cultos; estudar as questões que mais particularmente interessam ao nosso paiz; e pugnar pela união, dignidade e independencia da nossa profissão. Não promettemos pouco, de certo; mas, se não medimos mal as

\footnotetext{
${ }^{9}$ Esse grupo de médicos formado na década de 1860 recebe, já no século XX, a nomenclatura de "Escola Tropicalista Baiana". Tal terminologia ganha ênfase sobretudo após publicação, em 1952, do livro "A Escola Tropicalista Bahiana", de Antônio Caldas Coni e "The Tropicalist School of Medicine of Bahia, Brazil, 18691889" de Julyan Peard, publicado em 1997. Por critérios etimológicos de organização, no sentido de separar o grupo de médicos ligados ao nosso periódico objeto de investigação de outros médicos atuantes na Bahia mas não ligados ao mesmo, e também partindo de reflexões que compreendem "escola" como grupo não necessariamente coeso, nos sentimos fortemente tentados a adotar a nomenclatura. Porém não o fazemos, a partir da concordância com vieses como o de Flávio Coelho Edler (2002), que criticam o termo "Escola" por acreditarem que este reduza o papel de outros grupos médicos do período, principalmente quando se tem em vista que a $G M B$ recebe colaborações de médicos de fora da província, e as próprias contradições internas contidas no grupo de editores e colabores da Gazeta Médica da Bahia.
} 
nossas proprias forças, e se não contamos demasiado com o apoio e auxilio dos nossos colegas, a Gazeta Medica não sera d'esta vez uma tentativa irrealizável e infructifera. ${ }^{10}$

É possível discorrer sobre um sentido político do jornal, que buscava legitimar uma "classe médica", que se destacaria das demais por sua missão especial de colaborar para o progresso por meio da ciência.

De acordo programa de lançamento, a $G M B$ teria a responsabilidade de, a partir da troca de conhecimentos a nível internacional, decidir as questões que mais interessariam ao Brasil. Esta observação nos permite inferir que à medicina do período eram atribuídas, também, funções sociopolíticas que ultrapassavam os propósitos de descoberta de doenças e manutenção da saúde. Cabe notar que a demanda pela união da classe médica significa que havia um tipo de "desunião" - essa provavelmente se refere às disputas explicativas para as causas das doenças. Objetivo maior evoca a união da classe médica em nome do progresso, ainda que não aponte em que aspecto deve ocorrer essa união ${ }^{11}$.

A luta pela "dignidade da profissão" parecia indicativo da constante ocorrência de outras explicações e práticas de cura, não autorizadas pela ciência.

É justamente pensando em um contexto marcado por debates entre explicações diversas sobre doenças, onde não se podia identificar a harmonia no que concerne à indicação de métodos científicos e de um só tipo de prática médica, ou mesmo de uma só medicina, bem consolidada, que buscamos problematizar os escritos sobre higiene pública na GMB.

A fundação do periódico é justificada pela necessidade de se criar, na Bahia, um órgão competente para tratar de uma "literatura médica"12. Num momento onde a própria ideia do que era "medicina" estava sendo construída e várias práticas de cura, científicas ou não, vigoravam num mesmo contexto, a $G M B$ foi vista por seus idealizadores como um lugar destinado aos escritos dos "verdadeiros" médicos e da ciência que professavam como verdade. Tal literatura médica seria responsabilidade dos esculápios diplomados.

${ }^{10} \mathrm{GMB}, 1866: 2$.

${ }^{11}$ Neste trecho retomo reflexões contidas em monografia que apresentei em 2015, na condição de trabalho de conclusão de graduação: QUEIROZ, Vanessa de Jesus. Entre faladores e operários da ciência: o charlatanismo na Gazeta Médica da Bahia, 1866-1870. 2015. 54 f. Monografia (Bacharelado e Licenciatura em História) Universidade de Brasília, Brasília, 2015, pp. 36-37. Disponível em: < http://bdm.unb.br/handle/10483/12409>. Acesso em maio de 2017.

12 Vale recordar que na década de 1860 havia poucos jornais médicos em circulação no Brasil, sendo os dois mais expoentes: Na Corte os Annaes Brasilienses de Medicina (periódico publicado desde a década de 1830) e, a partir de 1866, a Gazeta Médica da Bahia. 
Em 1860 cada número da Gazeta Médica da Bahia possuía em média 12 páginas, contendo informações variadas que iam desde descobertas e métodos de cura no Brasil e na Europa, a críticas diversas ao ensino da medicina nacional. Todas as edições apresentavam um summario contendo indicação das seções temáticas presentes em cada edição. De um modo geral, as seções temáticas mais frequentes eram: Trabalhos Originaes, Registro Clinico, Medicina, Excerptos da Imprensa Medica Estrangeira, Noticiario, Correspondencia, Correspondencia Scientifica e Bibliographia. Antes da primeira seção apresentada havia, quase sempre, um tipo de introdução, que não recebia tal nome, a não ser no primeiro número, e continha informações das mais variadas. Não eram raros os artigos que versavam sobre higiene pública aparecerem nesta parte introdutória. Trechos extraídos de outras gazetas médicas, com destaque as inglesas e portuguesas, bem como de jornais norte-americanos, eram frequentes. Quanto ao preço, o número avulso custava 500 rs; para província os preços anual, semestral e trimestral eram, respectivamente: $8 \$ 000,5 \$ 000$ e $3 \$ 000$, para fora da província: $10 \$ 000,6 \$ 000$ e $4 \$ 000^{13}$.

Desde a primeira edição da $G M B$ é clara a intenção dos editores do jornal ${ }^{14}$ de elencar a higiene pública como importante agenda, que deveria tornar-se prioridade estatal, para combater e evitar as doenças:

Já não é uma utopia, nem um bello sonho o congresso ou conferencia sanitária internacional!.. Devida a previdente e sabia iniciativa do Governo Francez, acceita por quasi todos os Governos, que n'isso interessavam os quaes alli são dignamente representados, e de esperar- que n'aquella illustrada reunião ventile-se e discuta-se cabalmente o complicado problema, que lhe foi submetido, e que da solução das questões, que a ele se prendem emanem providencias reaes e práticas, que ponham em salvaguarda a saude dos povos [...] unicamente desejamos registrar nas páginas do nosso Jornal está sucinta notícia sobre um assumpto de tão subida importância que desafiou a atenção de quase todos os Governos; e, ao mesmo passo, deplorar que a medicina Brasileira não tenha seu representante n'aquelle humanitario Congresso..- Como explicar esta falta? - Será porque estejamos garantidos d'uma nova invasão da cholera-morbus? Por certo que não. - Similhante falta somente pode ser attribuida a proverbial indiferença que mostramos

\footnotetext{
${ }^{13}$ Preços válidos para a década de 1860.

${ }^{14}$ Ao falarmos de "editores" nos referimos ao grupo responsável pelo conteúdo do jornal, não à configuração de impressão, formato de página e outros quesitos tipográficos, ainda que estes também fossem levados em consideração. A Gazeta Medica da Bahia era publicada por uma associação de facultativos sob a direção de um esculápio. Em nosso período analisado o jornal é dirigido por Virgilio Climaco Damazio (1838-1913), formado pela e professor da Faculdade de Medicina da Bahia e médico pessoal de Rui Barbosa e, a partir de 1868, por Antônio Pacífico Pereira (1846-1822), médico também formado pela Faculdade de Medicina da Bahia. Ambos nasceram em famílias de elite.
} 
para objetos de tal natureza: porquanto só na occasião do perigo é que acordamos, e chamamos pelo Santo da nossa devoção, conforme vulgarmente se diz (...). A missão da Conferencia sanitária interessa a todos os povos, que e essencialmente cosmopolita, porquanto não sera pequeno benefício- que, do concurso e da maior somma de luzes, que seja possivel reunir, derivem-se medidas, que, oportuna e regularmente aplicadas, extinguam ou limitem a renovação, os estragos frequentes ou periodicos do flagelo, que, adquirindo inaudito vigor em seu foco primitivo, em consequência do estado de abandono e embrutecimento, em que vivem os habitantes d'aquella região [Mecca], vém inocular-se no coração das nações civilizadas, trazendo as maiores calamidades $[\ldots]^{15}$

Ainda que o trecho acima preconize a necessidade de proteção contra uma ameaça específica, a cólera-morbo, podemos apresentar algumas considerações mais imediatas sobre a temática da higiene pública na gazeta. As palavras de José Goes Sequeira, lente de patologia geral da Faculdade de Medicina da Bahia e inspetor de saúde pública da província baiana, permitem observar que a higiene pública era agenda central do jornal. Primeiro, o elogio à sabia decisão do governo francês que, ao contrário do governo brasileiro, já teria compreendido a importância de um congresso sanitário internacional. Tal importância é necessariamente relacionada à manutenção da saúde dos povos, entendida como pauta importante dos Estados. Trata-se da defesa do princípio de que cuidar da saúde da população deveria ser premissa governamental. Para tal tarefa, o papel dos representantes da medicina seria essencial.

Podemos observar, também, a defesa da incompatibilidade entre civilização e doenças calamitosas. Nota-se, ainda, a demanda pela inserção do Brasil no rol das nações civilizadas, o que significava, entre outras coisas, inserir na agenda do Estado a preocupação com a higiene pública. Por fim, observamos que, de certo modo, Goes Sequeira pede ao governo do Império auxílio para combater o costume de "clamar ao santo da devoção", visto que mais efetivo seria proteger-se dos males de uma moléstia por meio da medicina científica e preventiva, não atuando apenas na situação do perigo.

A questão da higiene pública como agenda central da $G M B$ ganha mais força quando revelamos que parte de seus escritos considerava verdadeira a teoria miasmática, que versava que as moléstias eram causadas por partículas venenosas e podres (SILVA PINTO, 1832) que pairavam no ar (podendo provir da água, do solo, de emanações atmosféricas, cadáveres abandonados, etc). Tal teoria ainda vigorava com algum sucesso na década de 1860 . Outras

${ }^{15} \mathrm{GMB}, 1866: 4$. In matéria intitulada "Congresso Sanitario Inter-nacional: nenhum representante por parte da medicina brasileira", de autoria de Goes Sequeira. 
teorias, como as das correntes contagionista e helmintologista, por exemplo, também ocupavam seu lugar na disputa explicativa. Explicações mistas não eram raras na GMB. Doenças eram relacionadas a ambientes sujos e maus hábitos sanitários.

\begin{abstract}
A missão da hygiene, quando por seus conceitos e preceitos procura esclarecer e guiar o homem e as populações, afim de que se ponham em salvaguarda, e previnam os males que as ameaçam, é, com effeito, a mais bella e importante. Se negligentes e surdos, como somos as suas vozes e advertencias, não recebemos quasi sempre a punição das nossas faltas, é, porque, por um favor providencial, a natureza, segundo phrase d'um médico escritor notavel, tem mais compaixão da humanidade do que a propria humanidade de si mesma; porem muitas vezes quando estamos distrahidos, engolfados em prazeres, e occupações diversas, la nos vem surprehendermales, e incommodos que nos amarguram a existência, os quaes nos entanto, poderiam em tempo ser prevenidos $(\ldots)^{16}$
\end{abstract}

O trecho acima é publicado durante o primeiro ano de circulação do jornal. O destaque concedido à data não é trivial, sobretudo quando refletimos que os responsáveis pela gazeta a modulavam segundo a eleição de assuntos que consideravam importantes aos seus propósitos de torná-la competente literatura médica, que preencheria a lacuna de imprensa médica na Bahia e no Brasil. Higiene pública era importante demanda que aparecia logo nos primeiros números do jornal.

E aparecia com um papel importante, na verdade, uma missão: a de esclarecer e guiar os homens e as populações, a partir da prevenção contra os males. O trecho não explicita, mas é pertinente perguntar: quem executaria a referida missão? Os médicos, operários da ciência. Porta-vozes das regras da higiene pública, tornariam a população menos dependente de favores divinos. Guardiões da prevenção, possibilitariam uma existência mais agradável, protegendo a humanidade de suas inexoráveis vulnerabilidades e deslizes- distrações, prazeres e ocupações diversas-, que ocasionavam incômodos à vida saudável. Missionários, reduziriam os riscos inerentes aos tempos em que preceitos preventivos não foram adotados de forma satisfatória. A missão da higiene traduzia-se na missão dos propagadores de suas regras. Trata-se da legitimação de função social da classe médica a partir de melhorias que a higiene pública poderia oferecer.

Em edição de 31 de outubro de 1868, encontramos transcrição de relatório intitulado “estado sanitario da cidade da Bahia". Nele, conta-se que o inspetor de saúde pública, Goes

${ }^{16}$ GMB, 1866: 66-7, grifos nossos. 
Sequeira, organizou uma reunião com outros esculápios para melhor analisar o estado sanitário da Bahia. É dele que extraímos o trecho a seguir:

O testemunho unanime dos collegas presentes foi: que ha alguns mezes se tem manifestado n'esta cidade notavel predomínio das affecções do tubo digestivo mormente diarrhea e camaras de sangue, e que ultimamente se observam numerosos casos de dysenteria, revestindo as vezes as mais graves formas d'esta doença, e constituindo uma verdadeira epidemia; que, alem das numerosas causas predisponentes ordinarias geraes e individuaes , reputavam a elevada temperatura a que estamos sujeitos ha muito tempo e sem interrupção, como um dos primeiros factores na produção dos effeitos de numerosas causas que, sem esta circumstancia, ficariam talvez inactivas, taes como as exalações miasmaticas e putridas,a deterioração das aguas, dos alimentos, etc.; que convinha promover quanto fosse possivel, e com brevidade, mais activa e mais efficaz limpeza das cidades e das habitações, a desinfecção dos focos d'emanações putridas não susceptiveis de remoção prompta, aconselhar a dispersão dos alumnos de casas de educação densamente habitadas, etc.; finalmente que se instruísse o povo no modo de evitar o mal, ou de attenuar os seus effeitos, mediante a observância possivel das regras da hygiene, quer no que respeita as pessoas, quer nos que se refere à alimentação, e hábitos de temperança $(\ldots)^{17}$

O trecho está alocado numa subseção intitulada "Hygiene Publica". Aproveitamos para esclarecer que nem sempre esta seção existia, com esta nomenclatura. Grande parte das vezes, os textos sobre higiene pública apareciam em seções principais do jornal (Trabalhos Originaes, Noticiario, Correspondencia Scientifica, Excerptos da Imprensa Medica Estrangeira, dentre outras), caracterizando-se como assunto frequente durante o período aqui analisado.

O relatório evoca a autoridade de um conjunto de médicos para respaldar as assertivas de Goes Sequeira. Duas considerações mais imediatas podem ser feitas: 1) Quanto maior o número de observações profissionais relatadas, maiores as chances de uma hipótese ser considerada uma verdade científica; 2) Um grupo restrito se auto-afirma para tratar de assuntos que afetam a vida das demais pessoas da população. Alguns médicos reunidos chegam ao consenso de que uma moléstia adquiriu proporções epidêmicas. Além de identificarem um problema que impõe como demanda, por eles definida a partir de suas observações, sugerem medidas a serem tomadas. Tais medidas deveriam ser aplicadas ao

${ }^{17}$ GMB, 1868:61, grifos nossos. 
grupo maior, à população. Notemos, ainda, que a ocorrência de moléstias faz parte do conceito de estado sanitário.

As medidas instrutivas mencionadas, filhas dos preceitos da higiene pública, afetariam diversas esferas da vida pública, a exemplo da limpeza das ruas da cidade; e privada das pessoas, a exemplo da limpeza das casas e observação dos hábitos de temperança e alimentação.

O conceito de higiene pública adotado na Gazeta Medica da Bahia desliga-se de concepções que a reduzem ao binômio sujeira e limpeza em seus sentidos literais apenas.

É possível definir higiene pública como o conjunto de normas sanitárias que devem ser seguidas em nome da manutenção do bem comum, mensurado pela ausência de doenças e problemas causados por fugas a tais normas. A elaboração, bem como a execução e a manutenção das regras da higiene, enseja um campo ora conflituoso, ora pactual, de debates que envolvem diversas parcelas sociais.

\section{A carne como elo da corrente relacional da higiene pública na $G M B$ na década de 1860}

No número 9 da $G M B$, datado de 10 de novembro de 1866, foi publicado ofício que o Dr. Goes Sequeira dirigiu à presidência da província baiana acerca das qualidades da carne distribuída ao consumo público. O seguinte comentário antecede a transcrição do ofício:

O juízo authorisado do nosso colega, formulado officialmente, não só justifica as queixas da população d'esta capital contra a má qualidade da carne ultimamente distribuída para alimentação publica, mas ainda confirma a opinião, de há muito formulada por pessoas competentes, acerca das más condições de salubridade do matadouro publico, e dos inconvenientes de sua conservação quasi no centro de uma freguesia populosa [...]

O trecho acima expõe tentativa de intervenção de representantes da saúde pública na vida quotidiana. Estes, autorizados pela ciência da higiene, confirmaram e explicaram as reclamações populares contra a má qualidade da carne "ultimamente distribuída para alimentação pública". Aparece, de certo modo, a concepção de que a população sabia reclamar, mas precisava de alguém que melhor explicasse suas queixas. A explicação satisfatória, embasada na autoridade da ciência da higiene, era o que concedia a Goes Sequeira maior quinhão do que as demais pessoas para falar sobre as condições da carne.

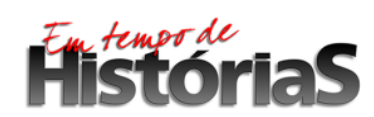

(PPGHIS/UnB) №. 31, Brasília, Ago - Dez 2017 ISSN 2316-1191 
Gabriela dos Reis Sampaio, falando sobre a dificuldade de coerência entre os próprios órgãos oficiais ligados a saúde pública, o que dificultava também a implementação de suas medidas como políticas públicas eficientes, nos informa:

[..] as autoridades enfrentavam sérios problemas na implantação das medidas indicadas pelos higienistas. Por mais rigorosas que fossem as prescrições dos agentes da higiene, elas eram frequentemente barradas por questões que escapavam ao seu controle, ligadas muitas vezes a hábitos e crenças bastante antigos de diferentes grupos sociais $[\ldots]^{18}$

As autoridades não conseguiam executar as indicações dos médicos versados na ciência da higiene. Em meio às tais "questões que escapavam a seu controle" podemos pensar em recusa popular aos novos métodos científicos higiênicos, ineficiência de medidas propostas, conflitos internos entre médicos e autoridades fiscalizadoras, dentre outros.

Goes Sequeira assim conclui seu ofício:

Se porventura se houvesse realisado a remoção do matadouro publico, como há 12 annos foi aconselhado pela extincta Commissão de Hygiene Publica, de que eu fazia parte [...] poderíamos possuir um edifício d'esta natureza, construido com aquellas condições hygienicas peculiares, e que são de mister; infelizmente, porem, as Municipalidades e Administrações que se seguiram aquellas, disso não cuidaram, e pois, ainda hoje vemos permanecer, quasi no centro d'este vasto povoado, um similhante estabelecimento, o qual, a despeito de quaesquer trabalhos e melhoramentos que n'elle se façam, achando-se em perfeito antagonismo com as leis e preceitos que a hygiene publica sabia e previdente prescreve, sera sempre um pernicioso foco de infecção, uma causa perenne de insalubridade[... $]^{19}$

As ações dos órgãos oficiais de saúde pública não mantinham continuidade tampouco cooperação mútua constante. Instâncias municipais, administrações e operários da ciência nem sempre chegavam a um consenso sobre as medidas a serem tomadas. A falta de concordância atrapalhava o papel da higiene, autoridade fundamental ao objetivo de manter a população salubre. Os doze anos de recomendação não cumprida são demonstrativos da dificuldade de implantar a classe médica como efetiva, além de oficial, no que concerne ao tratamento de assuntos de saúde pública. O campo oficialmente reconhecido pelo governo

\footnotetext{
${ }^{18}$ SAMPAIO, 2001:112
}

${ }^{19}$ GMB, 1866:99 
imperial parecia não ser tão bem amparado por este, tampouco pela população, no cotidiano baiano.

É frequente a aparição de documentos oficiais, a exemplo de ofícios e relatórios sobre estado sanitário, na Gazeta Medica da Bahia. Estes eram, geralmente, redigidos para serem enviados à Junta Central de Higiene Pública, no Rio de Janeiro, de acordo regulamento número 828, de 29 de setembro de $1851^{20}$. Eram publicados na $G M B$ porque seus responsáveis achavam pertinente que o assunto estivesse presente no jornal. A publicação destes relatórios nos leva a duas reflexões: 1) Que a origem destes documentos oficiais evidencia uma rede relacional e hierárquica entre órgãos oficiais da corte (RJ) e das províncias. 2) É cabível nos indagarmos sobre os porquês de documentos oficiais serem reproduzidos numa gazeta médica.

Prossigamos com alguns esclarecimentos sobre o decreto ou Regulamento de 29 de setembro de 1851. Este altera o nome da Junta de Higiene Pública ${ }^{21}$ para Junta Central de Higiene Pública ${ }^{22}$ e define a seguinte disposição hierárquica de atribuições:

Art. $2^{\circ}$ Nas Provincias do Pará, Maranhão, Pernambuco, Bahia e Rio Grande do Sul haverá Commissões de Hygiene Publica, compostas de tres membros, nomeados pelo Governo, que d'entre os mesmos designará o Presidente; nas outras Provincias haverá somente Provedores de Saude Publica. Art. $15^{\circ}$. Os meios necessarios para a policia sanitaria dos Portos, e as providencias para os casos extraordinarios, de que trata o Art. $8^{\circ}$ do mencionado Decreto de 1843, serão apresentados á Junta Central ou ás Commissões, que deliberarão a respeito de sua conveniencia. As Commissões communicarão suas decisões á Junta Central e se conformarão com as instrucções, que por esta lhes forem dadas. Nos casos porêm em que for necessario tomar medidas promptas, serão logo executadas as decisões das Commissões, não deixando por isso de as communicar á Junta Central, que as transmittirá ao Governo. Art. 47. A Junta Central, as Commissões, e os Provedores de Saude Publica terão o maior cuidado em investigar as causas da

\footnotetext{
${ }^{20}$ Que manda executar o regulamento da Junta de Hygiene Publica, criada por Decreto de 14 de dezembro de 1850. Versa seu $82^{\circ}$ artigo: “As Commissões e Provedores enviarão todos os annos até o fim de janeiro a Junta Central hum relatorio circumstanciado do estado sanitario das respectivas Provincias, com todos os esclarecimentos que pela Junta Central forem exigidos. Esta, com os relatorios provinciaes, e com os da Côrte e Provincia do Rio de Janeiro, formulará hum geral, que remetterá ao Governo". Disponível em: $<$ http://www2.camara.leg.br/legin/fed/decret/1824-1899/decreto-2052-12-dezembro-1857-558221publicacaooriginal-79207-pe.html>. Acesso em maio de 2017.

21 “Criada pelo decreto n. 598, de 14 de setembro de 1850, a Junta de Higiene Pública tinha por atribuição propor o que fosse necessário para a salubridade nas cidades, bem como indicar medidas que se convertessem em posturas municipais e exercer a polícia médica nas visitas às embarcações, boticas, lojas de drogas, mercados, armazéns e em todos os lugares, estabelecimentos e casas que pudessem provocar dano à saúde pública". (CABRAL, 2014). Disponível em: <http://linux.an.gov.br/mapa/?p=7270>. Acesso em maio de 2017.

22 Ver Art. $1^{\circ}$ do Decreto número 828 de 29 de setembro de 1851 . Disponível em: < http://legis.senado.gov.br/legislacao/ListaPublicacoes.action?id=79316>. Acesso em maio de 2017.
}

\section{Filistorias}


insalubridade geral ou parcial de algum lugar, em observar o curso das molestias reinantes particularmente das contagiosas, e em geral empregar a maior vigilancia sobre tudo que diga respeito á saude publica. Art. 80. As Autoridades Sanitanias se empenharão com todo o desvelo na execução dos $\S \S 1^{\circ}$ e $2^{\circ}$ do Art. $4^{\circ}$ da Lei de 14 de Setembro de 1850 . Os Provedores, porêm, quanto á indicação de medidas que devão ser expostas ás Camaras Municipaes, deverão communica-las aos Presidentes de Provincia que, nomeando Commissões extraordinarias de tres membros, compostas de Medicos e Cirurgiões, e na falta destes de Boticarios ou outras pessoas habilitadas, e ouvindo o seu parecer, as remetterão ás Camaras Municipaes para que estas as reduzão a Posturas. ${ }^{23}$

A alteração nominal, bem como a disposição configurada demonstrada pelos artigos selecionados, faz parte de esforços de centralização: Na Corte estaria a Junta Central, em algumas províncias estariam Comissões, em outras apenas um provedor da saúde pública. Todas as instâncias autorizadas pelo Governo Imperial. Os artigos evidenciam a seguinte ordem de reporte: Provedores $\rightarrow$ Comissões $\rightarrow$ Governo da Província $\rightarrow$ Junta Central $\rightarrow$ Governo Imperial. Em casos extraordinários (de epidemias, por exemplo), as comissões poderiam agir sem esperar o aval da instância maior, contudo a prestação de contas era imprescindível.

Do papel ao cotidiano as coisas parecem não terem ocorrido conforme esperado. Em 1857 surge decreto que altera algumas disposições do Regulamento de 1851 . Versa o artigo $9^{\circ}$ do Decreto número 2052, de 12 de dezembro de $1857^{24}$ :

Ficão extinctas as commissões de Hygiene Publica; e em seu lugar se creará em cada Provincia hum Inspector de Saude Publica; passando a tomar a mesma denominação os Provedores de Saude publica. Em quanto não se nomearem os Inspectores de Saude nas Provincias em que existem actualmente Commissões de Hygiene suas funcções serão exercidas pelos Presidentes das mesmas Commissões.

O disposto iguala inspetores e provedores de saúde pública, mas mantém a submissão destes à Junta Central. Quanto a esta, as alterações referem-se majoritariamente a atribuição de funções ao presidente da Junta, que continua submissa ao Governo Imperial. A nova disposição, grosso modo, resume-se em: Inspetores de Saude Publica $\rightarrow$ Governo da

23 Decreto 828, de 29 de setembro de 1851, Disponível em: < http://legis.senado.gov.br/legislacao/ListaPublicacoes.action?id=79316>. Acesso em maio de 2017.

${ }^{24}$ Approva o Regulamento desta data, pelo qual se alterão algumas disposições do da Junta Central de Hygiene Publica de 29 de setembro de 1851. Disponível em: <http://www2.camara.leg.br/legin/fed/decret/18241899/decreto-2052-12-dezembro-1857-558221-publicacaooriginal-79207-pe.html>.Acesso em maio de 2017. 
Província $\rightarrow$ Junta Central de Higiene $\rightarrow$ Governo Imperial. É importante ressaltar que esta ordem não é estatística. O esquema de setas aqui utilizado, apenas objetiva melhor ordenação das ideias propostas para enfatizar hierarquias.

O Regulamento vigorou até a década de 1880. Sua vigência não representa coerência entre leis no papel e sua execução na prática. Exemplos de falhas são identificados em edições da Gazeta Medica da Bahia. No número 16, de 25 de fevereiro de 1867, encontramos transcrito documento oficial intitulado "relatorio acerca do estado sanitario d'esta província (BA), durante o anno de 1866, apresentado a Junta Central de Hygiene Publica, pelo Dr. José de Goes Siqueira". O documento, que informa sobre ocorrência de doenças e sobre asseio na província, é iniciado com a seguinte justificativa: "Em virtude do que dispõe o regulamento de 29 de setembro de 1851, passo a relatar a $V$. Ex. o que há decorrido acerca do estado sanitario d'esta província, durante o anno findo" ${ }^{25}$. O escrito evidencia que oficialmente buscava-se cumprir o disposto no Regulamento. Porém alguns problemas apresentavam-se.

As diversas demandas da $G M B$ pelo cumprimento das regras de higiene e apoio governamental (do governo da província, mas sobretudo do Imperial) aos médicos, como vimos nos textos que versam sobre a ausência de representante brasileiro em congresso sanitário internacional e permanência do matadouro público no centro de freguesia populosa, são evidencias de falhas no funcionamento proposto.

Já foi dito que objetivo principal de lançamento da Gazeta Medica da Bahia estava relacionado a cuidados com uma literatura médica, lugar para os escritos dos verdadeiros médicos e da medicina científica que professavam como verdade. A necessidade de união de uma classe médica também é preconizada no jornal, que afirma ser seu público-alvo um "publico illustrado e especial"26

Entrando em caminhos de resposta sobre porquês de documentos oficiais serem publicados numa gazeta médica, enfatizamos a necessidade de tomar cuidado com o que se entende por público ilustrado. É necessário problematizar a restrição de público-alvo. Ilustrados não eram só os médicos. Um dos pontos que justifica nossa assertiva é justamente as publicações de documentos oficiais na Gazeta.

\footnotetext{
${ }^{25} \mathrm{GMB}, 1867: 189$

${ }^{26}$ GMB, 1866:3
} 
Uma das disposições do Regulamento de 29 de setembro de 1851 trata do envio de relatórios sobre as condições sanitárias das províncias à Junta Central de Higiene Pública. A publicação desses documentos na Gazeta Medica da Bahia parece fazer parte do esforço de legitimação da atuação da classe médica em dois sentidos: 1) frente ao governo, como reforço ao cumprimento de seu papel. Podemos pensar, também, na gazeta como espaço que informa os médicos sobre suas obrigações.; 2) frente a outros, se auto afirmando como órgão autorizado pelo Estado. É plausível o questionamento sobre quem realmente lia a GMB. Tendo em vista o índice de analfabetismo das camadas populares, acreditamos se tratar de um público majoritariamente ilustrado de profissionais, mas que não necessariamente só médicos. O alcance à população não ilustrada parece, inicialmente, não ser objetivo primário.

Tendo em vista a correspondência da GMB com jornais estrangeiros, a publicação destes documentos poderia ser, ainda, forma de comunicar que no Brasil moviam-se esforços em nome do progresso pela via da medicina científica, onde estava inserida a higiene pública de que falava o jornal. Tratava-se da tentativa de inserção do país no rol das nações civilizadas que prezavam pelos preceitos da higiene.

Além da publicação de documentos oficiais, notícias diversas eram publicadas pelas seções da gazeta. Nos detenhamos em uma destas, datada de 25 de janeiro de 1867, intitulada "Extracto Carnis". Extracto Carnis era um composto fabricado pelo processo de um esculápio do Rio Grande do Sul chamado Ubatuba. Este teria imitado o processo de fabricação de um barão químico alemão ${ }^{27}$. "Uma libra do extracto corresponde a uma arroba de carne, e contem sob forma concentrada, os seus principaes elementos nutritivos (...) meia onça é sufficiente alimentação para um homem(... $)^{28}$. O derivado de carne, aprovado pelo inspetor de saúde pública da província, Goes Sequeira, seria uma ótima pedida aos “convalescentes, aos viajantes, e n'aquelles casos de doença em que é necessaria uma alimentação sadia e nutriente sob diminuto volume" ${ }^{29}$, numa província como a Bahia, onde as carnes verdes quase sempre estavam em mau estado. Ponto negativo do produto seria seu alto preço. É concedido algum crédito à opinião do Dr. Ubatuba, que diz que aquele teria propriedades curativas contra a tuberculose. Ainda assim, pede-se que os colegas de profissão da Bahia testem o produto e remetam à $G M B$ suas opiniões.

\footnotetext{
${ }^{27}$ Barão Liebig.

${ }^{28}$ GMB, 1867:166

${ }^{29}$ GMB, 1867: 167
} 
O composto alimentício recebe aval do inspetor de saúde pública. A recomendação do uso do produto é justificada sobretudo pelo mau estado da carne verde, uma das principais bases alimentares da Bahia. Saúde pública era ligada à higiene, higiene englobava alimentação. $\mathrm{O}$ alto preço do produto pode ser empecilho para o acesso das camadas mais pobres, o que demonstra a tentativa de influência dos esculápios em um dos aspectos mais importantes da vida das camadas populares: a alimentação. Este aspecto também envolvia a indústria de fabricação do produto. Trata-se de uma influência sociocultural e econômica. É válido perceber que o convite aos demais colegas para testarem o produto mostra que nem as palavras do inspetor de saúde pública, tampouco o método do esculápio do Rio Grande do Sul, eram inquestionáveis, ainda que embasadas em ciência.

Em edição de 30 de junho de 1868, na seção Noticiario, lê-se texto intitulado "Tentativa para a introducção da carne de cavallo, em Londres" ${ }^{30}$. Trata-se de trecho extraído do jornal português Escholiaste Medico, que analisa uma experiência culinária onde foram preparados vários pratos com carne de cavalo. O trecho louva a experiência por esta quebrar preconceitos, a partir da tentativa de inserção da nova carne no cardápio habitual, em épocas de escassez alimentícia.

Bem como a notícia sobre o Extracto Carnis, a da carne de cavalo é publicada na seção Noticiario. Os escritos desta seção costumam ser breves e trazem os mais diversos assuntos. Pensando em propósitos de organização do jornal, enfatizamos, novamente, que uma notícia só é publicada se aprovada pelos responsáveis pela $G M B$. O assunto da inserção de uma nova carne foi considerado cabível de aparição. Ainda que pensemos no tema do trecho como algo que pode ser desaprovado ou não seguido pelos esculápios da $G M B$, é assunto exposto, portanto considerado pauta importante, seja para concordar ou discordar. $\mathrm{O}$ aparecimento desse tipo de assunto evidencia a preocupação premente com os assuntos de alimentação.

No número 65, datado de 15 de abril de 1869, a GMB traz na seção Hygiene Publica, texto denominado "Fragmento de um officio redigido pelo Dr. João Pedro da Cunha Valle, medico da municipalidade, em que combate a opinião d'aquelles que attribuem às carnes fornecidas pelo matadouro publico a dysenteria epidêmica que tem reinado na capital

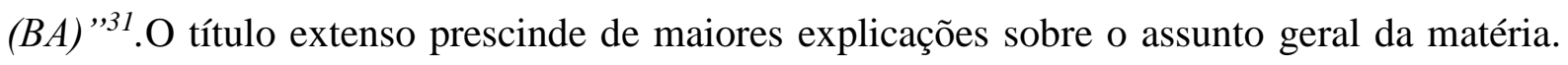

\footnotetext{
${ }^{30} \mathrm{GMB}, 1868: 287$
}

${ }^{31}$ GMB, 1869:202 
Cabe-nos explicar que João Pedro da Cunha Valle afirma, e para tal evoca autoridade de algumas bibliografias estrangeiras ${ }^{32}$, que o aparelho digestivo tem a capacidade de neutralizar efeitos nocivos da carne adulterada. Assim sendo, a epidemia de disenteria reinante até poderia ser influenciada pela insalubridade do matadouro e conseqüente má condição da carne, porém não de modo decisivo. Os miasmas e o clima são apontados como culpados pelo médico da municipalidade.

O testemunho de João Pedro da Cunha Valle conflitava com o do inspetor de saúde pública Goes Sequeira. Algumas reflexões ascendem do texto mencionado acima: 1) A GMB publica opiniões conflitantes, o que reforça nossa premissa de que o jornal não é uma coisa só, mas contempla pluralidades; 2) O assunto da carne permanece como importante questão na década de 1860; 3) Para explicar epidemias são considerados hábitos diversos, inclusive o de alimentação; 4) Há relação direta entre estabelecimentos públicos, a exemplo do matadouro, e hábitos da vida privada, a exemplo do consumo da carne; 5) Os esculápios, seja para defender a extinção do matadouro, seja para recusá-la, justificam suas ações pela necessidade de manutenção da saúde pública; 6) Havia conflitos entre os inspetores de saúde e autoridades municipais, o que nos permite pensar em outros níveis de conflito e reforça nossa hipótese de rede hierárquica, neste caso em sua face conflituosa. Além disso, podemos pensar na concomitância entre várias explicações teóricas num mesmo período e; 7) O jornal é palco de embates e debates.

\section{Algumas conclusões: A população como personagem indispensável e apassivado na $G M B$ em 1860 e outros versos}

Seja na recomendação de remoção do matadouro público não cumprida, seja nas sugestões de novos tipos de alimentos ou na defesa de que os miasmas superam a adulteração da carne quanto às nocividades epidêmicas, o que fica evidente é que alimentação era campo da saúde pública que os esculápios da higiene buscavam reger.

A manutenção da higiene pública é tida como exigência para a manutenção de uma boa saúde pública, que deveria ser responsabilidade governamental a partir de ações conjuntas. A saúde pública é campo de responsabilidade da administração pública em relação com classes médicas e sociais (ROSEN, 1994).

${ }^{32}$ Cita: Dr. Hamel, Dr. Morandi Dr. Levy, Sr M. Huzard, Delafond. 
Em 1860, a Gazeta Médica da Bahia foi lugar de luta por legitimação e, também, lugar de conflito. Produto de seu tempo reflete algumas das facetas de seu contexto. Este marcado pela construção de uma noção de medicina científica que, até se consolidar como ciência reconhecida, mais ou menos consensualmente no século $\mathrm{XX}$, seguiu um caminho tortuoso, enfrentando conflitos que tornavam impossível falar-se de uma só medicina ou de um consenso geral entre opiniões médicas no século XIX.

Neste grande campo das tais ciências médicas em construção, os esculápios buscavam seu lugar. Antes da definição de medicina chegar, as moléstias já grassavam e precisavam de explicações e soluções. É neste cenário que grandes questões, a exemplo de higiene e sáude públicas, ascendem. Explicar as causas dos males que acometiam o ser humano e modos de remediá-los: eis a justificativa da ciência médica, em construção, que é, por sinal, bem parecida com a dos praticantes de cura não diplomados.

Noutro canto deste artigo foi dito que, aparentemente, o público-alvo do jornal não era, primeiramente, as camadas populares. Contudo, devemos revelar que estas têm um papel fundamental à justificativa de existência do jornal e, consequentemente, dos esculápios a ele ligados. Todas as ações apontadas como necessárias e, de certa forma, a própria primordialidade da higiene pública, eram justificadas pela manutenção da saúde pública, ou seja, desta população geral. Sem a população que precisava ser cuidada, a necessidade de atuação dos operários da medicina não existiria.

A participação popular na $G M B$ em 1860 é apassivada, no sentido de que não se preconiza a atuação popular, a não ser no sentido de que esta precisa ser protegida, precisa ganhar voz contra as moléstias a que está sujeita. Incapazes de compreender a complexidade de tais males, dependeria dos médicos para fazê-lo. Infestada pelos relatos enganosos dos charlatões não diplomados, deveria ser livrada dos ineficientes curandeirismos.

Outros ecos do aparecimento do povo, como ator inevitável, ainda que apassivado, na $G M B$, são as constantes demandas pela legitimação da classe médica, cujo expoente exemplificador é o combate aos charlatões. Não devemos pensar nos conflitos internos entre autoridades e órgãos oficiais como definidores da situação. A legitimidade envolve diretamente o consentimento popular. É a partir da atuação na população, inclusive, que os esculápios poderiam demonstrar sua utilidade frente ao Governo Imperial.

Muitas das medidas da higiene pública quanto à alimentação falharam porque, na vida prática, o povo não tinha condições- sejam financeiras, sejam culturais, sejam de outra 
natureza-, de seguir as recomendações propostas. Anna Amélia Vieira do Nascimento (1986), falando da epidemia de cólera-morbo na Bahia em 1855, ressalta que recomendações profiláticas, que incluíam hábitos alimentares, feitas pelos higienistas, não puderam ser seguidas porque as normas propostas embasavam-se em considerações sobre um contexto europeu que não se aplicavam ao contexto brasileiro (poder aquisitivo, hábitos culturais, clima e outros fatores tornavam-nas incompatíveis). Talvez possamos entender a demanda da $G M B$, onze anos após a primeira epidemia de cólera na província, para participar de congressos internacionais de higiene justamente como esforços para resolver tais questões, o que não nos proíbe de pensar que o problema exposto por Ana Amélia ainda pudesse persistir. As possibilidades são múltiplas e os debates acerca da carne colocam a discussão num patamar acima da solução.

Os exemplos aqui analisados, que versavam sobre a salubridade da carne e de suas condições higiênicas de produção, bem como o conceito de higiene proposto na parte número dois deste artigo, nos mostraram que higiene pública para além de campo científico e/ou nosológico, era espaço de debates sociocultural, político e econômico. Higiene pública, a partir de sua relação direta de pré-requisito para a saúde pública, evidenciava uma rede extensa e complexa de pactos e conflitos que envolviam o objetivo de manutenção do bom estado sanitário. Este seria atingido quando o governo ouvisse as recomendações dos médicos, principalmente os da $G M B^{33}$, da higiene e os ajudasse a aplicá-las à população.

Passados dois séculos, lidamos com um novo episódio das condições de salubridade da carne como importante questão de saúde pública ${ }^{34}$. Advertindo sobre os perigos do anacronismo, ressaltamos a permanência da rede relacional em torno do assunto. Em contextos diferentes, em espaços diferentes, a salubridade da carne continua a ser questão que move uma extensa rede relacional que esbarra, necessariamente, em preceitos oficiais de higiene pública, que enfrentam resistências, impossibilidades e incertezas, demonstrando que, até hoje, higiene pública não é uma coisa só e enseja debates múltiplos.

\section{Referências Bibliográficas}

${ }^{33}$ Tendo em vista que nossas análises têm este jornal por objeto e que o grupo responsável por ele atuava em meio a outros grupos.

${ }^{34}$ Nos referimos a já mencionada Operação Carne Fraca. 


\section{Fontes}

\section{Notas oficiais}

ASCOM, ANVISA, BRASIL. Nota Sobre Operação Carne Fraca, 2017. Disponível em: $<$ http://portal.anvisa.gov.br/noticias/-/asset_publisher/FXrpx9qY7FbU/content/nota-da-anvisa-sobre-a-operacaocarne-fraca-/219201? inheritRedirect=false >. Acesso em Maio de 2017.

POLÍCIA FEDERAL, BRASIL. Relatório Operação Carne Fraca, 2017. Inquérito Policial $n^{\circ}$ 0136/2015$S R / P F / P R$. Disponível em: <http://politica.estadao.com.br/blogs/fausto-macedo/wpcontent/uploads/sites/41/2017/04/246_REL_FINAL_IPL1.pdf >. Acesso em Maio de 2017.

\section{Decretos}

BRASIL. Decreto n. 598, de 14 de setembro de 1850. Disponível em: <http://www2.camara.leg.br/legin/fed/decret/1824-1899/decreto-598-14-setembro-1850-559839publicacaooriginal-82251-pl.html>. Acesso em Maio de 2017.

_. Decreto n. 828, de 29 de setembro de 1851. Disponível em: < http://legis.senado.gov.br/legislacao/ListaPublicacoes.action?id=79316>. Acesso em Maio de 2017.

Decreto n. 2.052, de 12 de dezembro de 1857. Disponível em: <http://legis.senado.gov.br/legislacao/ListaPublicacoes.action?id=79316>. Acesso em Maio de 2017.

\section{Dicionários}

PINTO, Luiz Maria da Silva. Diccionario da lingua brasileira. Ouro Preto :Typographia de Silva, 1832. Disponível em: <http://www.brasiliana.usp.br/handle/1918/02254100>. Acesso em Maio de 2017.

\section{Jornais}

Annaes Brazilienses de Medicina(RJ) 1851-1885 (1860-1870). Disponível em: < http://memoria.bn.br/DocReader/docreader.aspx?bib=062014\&pesq=> Acesso em Maio de 2017.

Gazeta Médica da Bahia (edições diversas do período de 1866 a 1869). Disponível em: < http://www.gmbahia.ufba.br/index.php/gmbahia/issue/archive>. Acesso em Maio de 2017.

\section{Bibliografia}

CABRAL, Dilma. Junta Central de Higiene Pública. Arquivo Nacional, COGED, 2014. Disponível em: <http://linux.an.gov.br/mapa/?p=7270>. Acesso em Maio de 2017.

CONI, A. C. A Escola Tropicalista Baiana: Paterson, Wucherer, Silva Lima. Salvador, Tip. Beneditina, 1952.

EDLER, F. C. A Escola Tropicalista Baiana: um mito de origem da medicina Tropical no Brasil. In: História, Ciências, Saúde. Manguinhos, Rio de Janeiro, vol. 9(2):357-385, 2002.

LEVI, G. "Três histórias de família: os núcleos parentais". In: A herança imaterial. Trajetória de um exorcista no Piemonte do século XVII. Rio de Janeiro: Civilização Brasileira, 2000, 87- 130.

NASCIMENTO, A.A.V. Dez freguesias da cidade do Salvador - aspectos sociais e urbanos do século XIX. Bahia, Ed. UFBA, 1986.

PEARD, J. G. The Tropicalist School of Medicine of Bahia, Brazil, 1869-1889, Michigan, Columbia University, 1990.

ROSEN, G. Uma história da Saúde Pública. São Paulo: Unesp, 1994.

SAMPAIO, G. R. Nas Trincheiras da Cura. As diferentes medicinas no Rio de Janeiro Imperial. Campinas, SP: Editora da UNICAMP, 2001. 